REVIEW ARTICLE

\title{
Cheese: Food Perception and Food Choice
}

\author{
Lénia Rodrigues ${ }^{1}$, Maria Machado ${ }^{1,2}$ and Cristina Pinheiro ${ }^{1,2,}$ \\ ${ }^{1}$ Institute of Mediterranean Agricultural and Environmental Sciences (ICAAM), University of Évora, Évora, Portugal; \\ ${ }^{2}$ Institute of Mediterranean Agricultural and Environmental Sciences (ICAAM), School of the Science and Technology, \\ University of Évora, Évora, Portugal
}

\begin{abstract}
In light of the increasing interest in the economic and socio-political impact of the "traditional food' trend, it is essential to understand the determinant factors that lead to traditional consumer choices. The standardization of sensory quality evaluation methods marks the pressing need for food product certification, particularly foods with specific sensory characteristics, such as those with a Protected Designation of Origin (PDO). Consumer perception of particular foods, especially for foods that are culturally and socially contingent, such as cheese, must be understood as both a psychophysical reflex and a learned social practice. Consumers create their own perceptions based on the overall intrinsic or extrinsic cheese characteristics, mainly sensory characteristics that reflect others' attributes. These characteristics are normally linked to the specific cheese manufacture process. Some patents propose the use of adapted cheesemaking equipment (EP1982582A2), suitable for the manufacture of small-scale cheeses, such as some PDO cheese.

Thus, sensory evaluation of any kind of cheese is based, in the initial phase, on knowledge of the sensory methods for cheese evaluation and, in a second phase, on the familiarity of the cheese characteristics and verbalization of desirable and undesirable attributes.

This paper presents a case study based on the traditional food product, Évora cheese, assembled with PDO cheeses, whose sensory and physicochemical quality attributes are essential in order to obtain this designation and ensure the genuine properties that characterize them, as well as ascertaining exactly how they are perceived and further accepted by the consumer.
\end{abstract}

Received: March 03, 2017

Accepted: June 20, 2018

DOI:

DOI: $10.2174 / 2212798410666180705092257$

Keywords: PDO cheese, Évora cheese, sensory analysis, C. cardunculus, food choice.

\section{INTRODUCTION}

Understanding food choices involves understanding how consumers perceive food and how the diverse points of perception (sensorial, psychological, socio-economic) drive that choice. The main driver for human food is obviously hunger, but what we choose to eat is not determined exclusively by physiological or nutritional needs. The choice of food is a dynamic process built upon several determinants, namely (1) biological determinants (such as hunger, appetite and sensory aspects), (2) environmental determinants (such as cultural, social and economic environment) and (3) individual determinants (such as age, gender, personality and food experience) [1].

Regarding biological factors, when asked, most people say that their food choices are largely determined by taste, in other words, flavour, which includes smell and oral perception. Sensory-affective responses to the taste, smell, eyesight and texture of food are a major influence on food preferences

*Address correspondence to this author at the Institute of Mediterranean Agricultural and Environmental Sciences (ICAAM), School of the Science and Technology, University of Évora, Évora, Portugal; Tel: +351 266740 800; E-mail: ccp@uevora.pt and choices [2]. Palatability is proportional to consumer preference when eating a specific food. It is dependent on the sensory properties of the food, such as taste, smell, texture and appearance. Sweet and high-fat foods have an incontestable sensory appeal. In this context, sensory food-related characteristics, especially taste, are identified as one of the main determinants of food consumption [3].

The environmental factors include a set of external influences on the individual, resulting from factors that occur in their surrounding environment, which includes social, cultural, economic and other contexts [4]. Cultural factors have been reported to be one of the main factors underlying food choices [5-7]. Food consumption has a strong cultural component, as foods can be regarded as social vehicles that have moral significance and allow people to make social distinctions and establish social relationships [8]. Another example of cultural influence is related to religion, which is a determinant factor for certain types of foods and beverages [4]. Demographics, circumstances and habits interact with consumers' food purchasing behaviour, reflecting the increase in the consumption of local products, which leads us to perceive the purchasing decision attitude $[9,10]$. 
In relation to the social context, Hetherington and colleagues [11] showed that eating with family or other acquaintances increased the energy intake associated with food consumption, compared with people eating alone. The role of other people in this regard is much important, as they may help in choosing what is adequate or "ideal" to eat in a certain situation and contribute towards maintaining regular eating patterns and an adequate diet [12].

Another important factor is the accessibility of resources with regard to food choice. As such, limited financial resources may restrict the purchase of certain food products; physical and mental incapacity, transportation constraints, architectural barriers and living in a rural area may serve as obstacles that prevent people from having access to favourite food products and determine the purchase of alternatives of varying suitability, which in turn may influence habitual preferences [4]. Numerous scientific studies have been published on the concept of local food, consumer perceptions and consumers' willingness to pay for local food $[9,10]$.

In addition to external influences, there are intraindividual processes (cognitive, affective, behavioural, sensorial, physiological) that, in interaction with environmental processes and with the characteristics of food products, also determine preferences, choices and behaviours. In this context, individual factors such as age, gender, an individual's personality may have an impact on preferences and choices. Furthermore, different levels of knowledge and experience with regard to food-related issues may induce different types of behaviour in relation to food [1]. The role of attitudes concerning certain types of foods (e.g. their perceived benefits) is evident, as these may determine a positive, neutral or negative tendency towards certain food products $[4,13]$.

The purpose of this work is to review the relationship between consumer choice, preference for locally produced, traditional or culturally significant food and the intrinsic and extrinsic determinants that lead to the consumption of PDO food products. In this case, cheese is the regional food product under discussion, with the focus on Evora cheese. As such, this study emphasizes the relationship between the sensory evaluation, and cheese composition, which determines the emergence of consumer attributes and is important for understanding both consumer liking and consumer sensory perception.

\section{CHEESE SENSORY EVALUATION}

The sensory analysis of foods that are locally or organically produced, which are traditional, or culturally significant in some way presents a particular challenge. Several studies have examined the relationship between consumer perception or preference and extrinsic qualities, which are incorporated into the product through the production, for these kinds of products $[14,15]$.

The sensory evaluation of the cheese is based on the following three main attributes: appearance (shape, size, colour, eyes/holes), texture (firmness/hardness, cohesiveness, elasticity, adhesiveness and viscosity) and flavour (odour, taste and aroma) [16].

Appearance of a cheese is one of the purchase decision factors and is based upon its shape, size and packaging. The appearance and colour of the cheeses are characteristics assessed by sight and are key features of the attractiveness of the product. The appearance of the cheese comprises geometrical characteristics (shape, dimensions, weight) and macro-structural features (presence of eyes, cracks, stains). These characteristics are generally associated with specific operations that take place during the cheese-making process, the microbiological quality of the milk and/or cheese, the ripening conditions and certain metabolic effects that occur during the manufacturing process and/or maturation [17]. In terms of the shape, the cheese may be described as spherical, conical, tubular, round-cut or oval, cylindrical (flat side stages, rounded side stages, concave or convex), tall, short, long, parallelepiped (square section or rectangular section (square or rounded edges)) or pyramid trunk. For example, all Portuguese PDO cheeses are cylindrical [18].

With regard to the interior appearance of the cheese, the colour (intensity and uniformity), rind (thickness and connecting the folder), appearance (evenness, oiliness, humidity, presence of crystals) and eyes (number, size, shape, distribution) are all taken into consideration. Cheese colours naturally range from snow-white to deep yellow. Orange cheeses, such as Cheddar, are coloured with annatto - a tasteless, odourless natural vegetable dye - during manufacturing. The eyes may be mechanical or biological. Eyes of mechanical origin are the result of technological practices, whether desired or not. They have small rounded cavities with irregular edges and variable sizes. Eyes of biological origin are the result of the activity of microorganisms present in the cheese [19].

Cheeses may be rindless, display natural rinds or possess rinds that are produced by harmless mould. A rind varies in texture, thickness and colour. The rind zone is more or less dense depending on the duration of maturation. Cheeses that have ripened over time have thicker scabs. The colour of the rind is an indication of its variety, condition and quality. In all cases, the colour should be characteristic of the cheese type. Some cheeses have a rough, thick crust. This is due to salt drying on the surface and to changes in the coagulation process [20].

The rate of water release from the cheese varies according to salt content, so indirectly the salt is one of the factors involved in the external surface appearance of the cheese. Due to their degree of dehydration and high salt content, very ripening cheeses are usually smaller, sometimes with an irregular external surface, but have high energy conservation. Their appearance seems to be due to the heterogeneous process and extent of dehydration [20].

For each cheese type, and traditional cheeses are no exception, there is an expected dominant textural attribute. Thus, textural characterization is crucial as a first step in defining how uniform in quality, and thus how successful the cheese will be compared with similar products that may be chosen as an alternative by consumers. During cheesemaking, factors such as temperature, coagulation, $\mathrm{pH}$, humidity, fat and salt content contribute to the texture of the final product. For example, a high curd temperature leaves the curd springy and the resulting cheese will be rubbery, whereas a lower milk $\mathrm{pH}$ at the time that the coagulant is added results in harder cheeses [21]. 
The aroma and flavor of a cheese are the combination of a number of substances (amount and ratio) present in cheese. The diversity of substances which are present in cheese is explained by the complexity of the substrate, constituted by fat, protein and soluble in milk compounds but also the variety of enzyme systems able to act on this substrate. In fact, the mechanisms of formation of these compounds are mainly enzymatic, while the complexity of the microbial flora contributes to this diversity [19]. The most characteristic cheese odours are fruity, salty, spicy and bitter. Cheese with high humidity and a low salt level may allow the development of undesirable microorganisms and the development of undesirable odours and tastes. On the other hand, a high salt content and low humidity contribute towards preventing the occurrence of unpleasant tastes [20].

\section{METHODOLOGIES OF SENSORY ANALYSIS: MAIN GUIDELINES}

Numerous sensory evaluation methods and consumer testing ideologies are available, but some versions are applied based on three main aspects: the goal of the study, the samples, and the attribute to be evaluated. These determine the type of test, scale, assessors and the overall design of the experiment [22-24].

Several internationally accepted standards for general methods of sensory analysis available in highlighting: general guidance (ISO 6658, 2005, ISO 11132:2012), sensory vocabulary (ISO 5492, 2008), test room (ISO 8589, 2007), assessor's selection, panel training and monitoring procedures (ISO 8586-2012), sensitivity of taste (ISO 3972, 2011), hedonic tests (ISO 11136:2014), texture profile (ISO 11036:1994), and shelf life and food control (ISO 16779, 2015, ISO/CD 20613).

Sensory evaluation tests may be divided into two classes: affective and analytical tests. In affective tests, consumers have to answer questions like "Which product do you prefer?" or "Which product do you like?". Affective tests require a much larger panel size than analytical methods in order to ensure greater confidence in the interpretation of the results $[23,25]$.

The analytical tests are discrimination (or difference) and descriptive tests. Discrimination tests can be used to determine whether products or characteristics are different among samples (e.g. are products different?). The most common discrimination methods include the triangle test, the paired comparison test, ranking test and the duo-trio test. Descriptive tests are used to provide more comprehensive product profiles asking panellists to identify the different characteristics within the product and quantify characteristics (how much; how are they different?). A trained panellist must be used for descriptive tests. There are several different methods of descriptive analysis (Table 1), including the Flavour Profile Method, Texture Profile Method, Quantitative Descriptive Analysis, the Spectrum method, Quantitative Flavour Profiling and Free-choice Profiling [26].

There are three types of tests which can be used to answer some practical questions: profile, scaling and ranking $[24,27]$.
Nowadays, more advanced sensorial methods are used, especially with populations that cannot provide written or accurate verbalization of consumer perception [28, 29]. The methods of measuring emotion with questionnaires or gauging facial emotions via software, comprising autonomic evaluations and brain imaging methods as well as oral and visual self-reporting measures, are becoming more frequent in sensorial consumer tests applied to children, with the primary aim of understanding how consumers' emotional answers may be associated with the output of sensory analysis tests [28, 29].

\section{FOOD CHOICE: THE PARTICULAR CASE OF PDO CHEESE}

The quality of a cheese, according to Gilles and Lawrence [30], is determined by its visual appearance and texture, and essentially set by its smell and taste characteristics (taste and smell). The quality attributes of cheese are determined by its physical biochemical, microbiological and sensorial characteristics. The relative importance of these characteristics varies according to the type of cheese and is subject to the production system that determines to the specific features of such cheeses $[31,32]$.

Protected Designation of Origin (DOP in Portuguese) registration is a system that protects cultural and gastronomic heritage, ensuring the product's origin and uniqueness. PDO Portuguese cheeses are made using traditional, wellestablished cheesemaking processes, as described in the Malcata patent (EP1982582A2) [33], and are typically named after the region where they are manufactured. The product must have qualities or characteristics, which are determined by the region of production. The production and processing follow strict specifications established through traditional and ancestral know-how [21, 34, 35].

Some consumers of regional products are ready to pay a significant premium for a regional product with a protected designation of origin. This can partly be explained by their attitude towards the PDO/PGI (Protected Geographical Indication) protection label, which in turn is significantly influenced by the perception of the label, associated with quality, economic support, price and a specific oral sensation. A regional product of this kind is more likely to be consumed by consumers living in the region of origin of the product. Consumers consider such products as having higher value and buy them knowing the country/region of origin, but generally, only a small portion of the population understands what such a label means $[36,37]$.

The standardization and accreditation of sensory quality evaluation methods are crucial for the certification of food products, particularly those with specific sensory characteristics and those with a PDO [38]. PDO food products need to gain the acceptance of consumers while at the same time respecting their sensory quintessence. In many cases, these producers are small enterprises, being economically impossible for them to develop and introduce systematic quality control on the end product based on hedonic and analytical information [39, 40]. 
Table 1. Methods of descriptive analysis.

\begin{tabular}{|c|c|}
\hline Test & Description \\
\hline \multicolumn{2}{|r|}{ Discrimination Tests } \\
\hline Paired comparison test & $\begin{array}{l}\text { Samples are presented in pairs for comparison and detection of differences or preferences. The main advantage of } \\
\text { this test is its simplicity and less sensory fatigue. }\end{array}$ \\
\hline Triangle test & $\begin{array}{l}\text { Simultaneous presentation of two equal samples and one different, which is intended to identify. It is an applied } \\
\text { test when it is desired to identify small differences between samples. }\end{array}$ \\
\hline Duo-trio test & $\begin{array}{l}\text { Three samples are presented to the taster, one of which is identified as a reference, and the other two are ran- } \\
\text { domly coded, asking to identify which of the samples is the reference. }\end{array}$ \\
\hline Ranking test & $\begin{array}{l}\text { Simultaneous presentation of several samples to the panellists, who must arrange them in order (increasing or } \\
\text { decreasing) according to their preference or intensity of the characteristic being analysed. }\end{array}$ \\
\hline \multicolumn{2}{|r|}{ Descriptive tests } \\
\hline Flavour Profile Method & $\begin{array}{l}\text { A panel of four to six panelists, trained to precisely define the flavours of the product category in a } 2-3 \text { week } \\
\text { period. The selection criteria for the panel are particularly rigorous. The panel is then exposed to a wide } \\
\text { range of samples in the product category and during training panelists review and refine the flavour vocabulary. } \\
\text { Term definition and reference standard selection also occur during the training and the temporal order of attrib- } \\
\text { utes is recorded. }\end{array}$ \\
\hline Texture Profile Method & $\begin{array}{l}\text { The technique aims to allow the description of texture from first-bite through complete mastication and also } \\
\text { accounts for the temporal aspect of attributes. rated on scales to cover the range of sensations in foods, and scale } \\
\text { points are anchored with specific food products. }\end{array}$ \\
\hline Quantitative Descriptive Analysis & 10 to 12 panellist is used, for the description and quantification of all the sensorial attributes of a product. \\
\hline Spectrum method & $\begin{array}{l}\text { This method also known as "Universal Scale", is a universal descriptive tool based on the use of absolute refer- } \\
\text { ences for all type of products. It requires a long training period, whose length depends on the number of descrip- } \\
\text { tors and consequently the references to be used. }\end{array}$ \\
\hline Quantitative Flavour Profiling & $\begin{array}{l}\text { This technique concentrates on the description of flavour only, the descriptive language used is a common stan- } \\
\text { dardized flavour language developed by a panel of } 6-8 \text { people. }\end{array}$ \\
\hline Free-choice Profiling & $\begin{array}{l}\text { This method differs from the previous ones by the way the descriptors are established, where each taster develops } \\
\text { and uses his own list of descriptors respecting an evaluation protocol defined by the panel leader. It thus allows } \\
\text { solving problems resulting from cultural differences of the panellists in which different terms are used for the } \\
\text { same sensory perception, based on the assumption that panelists do not differ in their perceptions but merely in } \\
\text { the way in which they describe them. The distinct advantage is the avoidance of panel training, participants need } \\
\text { only to be able to use a scale and be consumers of the product under evaluation. }\end{array}$ \\
\hline
\end{tabular}

Sensory evaluation methodologies are essential in guaranteeing the quality, protection and promotion of PDO food products [41, 42].

To establish the sensory quality of a PDO food product and to define a process for its assessment, it is essential to connect scientific and market knowledge with area knowledge (kind of enterprise, production systems, product reference and product variability). The sensory laboratory staff and the sensory assessors should have training meetings to establish a specific attitude towards progress, both in terms of sensory reference definition and the evaluation method. The members of this group are a decisive element in ensuring the success of this task and should incorporate internal assessors or a mixed (external/internal) panel of assessors (e.g. processors, restaurateurs, gastronomic critics, consumers, supermarket sponsors) [38].

Moreover, the acceptance of sensory evaluation practices for PDO cheeses may provide strategic support that will help to preserve the uniqueness of each PDO cheese. With their specific characteristics and biodiversity, such designations encourage the rural population to remain where they are, especially in marginal areas.

In addition, this opens up the possibility for a new generation to foster an enterprising spirit of innovation and create added value, without losing their authenticity.

\subsection{The Particular Case Of Évora Cheese}

Évora cheese has been a PDO cheese since 1994. It is a farmhouse-style cheese made from raw ewe's milk, in the Alentejo region of southern Portugal. The cheese is ripened for at least 30 to 45 days, achieving a semi-hard or a hard consistency, with $6-8 \mathrm{~cm}$ diameter and a weight of $60-90 \mathrm{~g}$ (small size) or with a $12-15 \mathrm{~cm}$ diameter and a weight of $120-300 \mathrm{~g}$ (medium size). In the past, the small-size cheeses were produced for socio-economic reasons. According to 
Rivara, [43] they were made to be used as a daily payment to rural labourers.

The extensive system of sheep's milk production, the manufacturing process and the ripening conditions provide chemical and sensorial characteristics which contribute to the specificity of Évora cheese. The variability of milk composition, differences in salting procedures and uncontrolled storage conditions were a source of heterogeneity that affected cheese quality. These conditions determine the size characteristics, shape, texture and smell/taste flavour that influence the buying decision (food choice) and appreciation of consumers.

Research has been carried out to address Évora cheese and discriminating factors that confer specific characteristics, as perceived by a sensory panel and consumers [44].

Sensory evaluation of PDO Évora cheese was performed by an internal panel of 11 trained assessors ( 9 women and 2 men, aged 30-55) who belonged to the staff of the ICAAM (Institute of Mediterranean Agricultural and Environmental Sciences). They were selected in accordance with international standards (ISO, 8586-1:1993; 8586-2:1993; EA-4/09Acreditation for Sensory Testing Laboratories; NP EN ISO/IEC 1725:2000) and carried out a quantitative descriptive sensory analysis as reported by Piggott [16].

The typical flavour of sheep's cheese produced in the Évora region is, according to the panel's assessment of overall flavour, associated with a high intensity of piquant, ewe's milk flavour, with a salty taste and a low intensity of an acid, bitter taste and a musty, rancid flavour. Nowadays, consumers that know the characteristics of the "genuine" Évora cheese appreciate the hard, intensely flavoured cheese, but "mainstream" consumers tend to choose the semi-hard and less intensely flavoured versions, particularly those with a piquant ewe's milk flavour [17].

A biochemical approach to Évora cheese has shown some evidence that may correlate with cheese sensory perception and possibly explain certain attributes that determine this food choice by some consumers.

Évora cheese is characterised by high levels of lipolysis, compared with low proteolysis, presenting extremely high concentrations of fatty acids, esters and ketones responsible for the flavour intensity. Volatile components were detected, including terpenes, phytenes, limonene and indol, which are normally associated with cheese produced from the milk of grazing ewes [17].

The intensity of the proteolysis reached a maximum within the first month of maturation (like Fiore Sardo cheese), but afterwards, there was a decrease in parallel with a decrease in moisture and an increase in $\mathrm{NaCl}$ content. The concentration of amino acids is not very high compared with other known cheeses. The profile of amino acids allows discrimination, although not in a very obvious form, in terms of the age of the cheeses, the manufacturing period and the type of rennet used [17].

Lipolysis is very intense throughout the maturation period, and the development of a piquant taste was typically observed, as in Fiore Sardo manufactured with rennet paste.

According to the results of the volatile components analysis, Évora cheese is characterised by high lipolysis, presenting extremely high concentrations of fatty acids and considerable concentration of esters and ketones, which is also the case with surface-mould-ripening cheeses (e.g. Camembert) and blue-veined cheeses (e.g. Roquefort). These could indicate the determining role of yeasts and moulds in lipolytic activity in Évora cheese. They present components, although with very low levels of terpenes, phytenes, limonene and indol, they present components that are normally associated with cheese manufactured from the milk of grazing ewes. As such, this component could be considered to contribute towards making the method of producing Évora cheese unique.

The coagulation process with Cynara cardunculus L. for cheese-making is considered one of the most important factors in the quality of traditional Portuguese ewe's milk cheeses [45]. Cynara Cardunculus extract is the allowed rennet used by this PDO cheese, giving some specific flavours. In Évora cheese processing, sheep cheese manufactured with Cyanara cardunculus extract differs from sheep cheese made using animal rennet essentially in terms of the intensity of ewe flavour and the "typical flavour" (higher with Cynara Cardunculus). This sensory perception is supported in biochemical terms by the free fatty acids (FFA) profile (particularly short and medium-chain fatty acids) and components such as 3-methyl propanoic, 2-methyl butanoic, 3-methy butanoic (products of amino acid catabolism). Results of proteolysis were less evident on the basis of WSN (water soluble nitrogen), but significant effects were observed for TCA-soluble nitrogen, and amino acid profiles and their effect are greatly increased at 30 days (as lipolysis), while after 60 days the differences are less pronounced [17].

\section{CONCLUSION}

The food choice and consequently the consumer 's food reflect responses to a range of factors, not only based on physiological or nutritional requirements but also associated with biological, social, cultural, economic, individual determinants and sensory characteristics of the food products. In particular, when analysing the factors that motivate the decision and choice of PDO food products, we found that factors such as region, hand-made manufacture, family background issues, previously acquired information about the product and food habits are decisive in the food choice process.

The methodology used to evaluate the sensory properties of the food are an essential tool for assessing or predicting the food perception faced by different population groups. It is not unexpected that the emergent developments in food sensory analysis attempt to reproduce the consumer's perceptions and how diverse points of perception drive PDO cheese choices. In addition, sensory characteristics which can be etymologically recognised as unpleasant in PDOs may be recognised as pleasant, specific and differentiating for this kind of food. According to the Évora cheese panel's assessment, the perception of overall flavour is assumed as the "typical flavour", associated with a high intensity of piquant, lower ewe/animal flavour, moderate salty taste, and a low-intensity acid, bitter taste and musty and rancid flavour.

Nowadays, the market that is familiar with the characteristics of "genuine" Évora cheese appreciates its hardness and intense flavour, but "mainstream" consumers opt more for 
the semi-hard variety with a less intense flavour, and less piquancy in particular.

Hence, the consumer perception and a PDO food product may be assumed as a mix of socio-cultural learned practice, individual determinants and sensory characteristics.

\section{CURRENT \& FUTURE DEVELOPMENTS}

Ensuring the nutritional quality aspects and the typical sensory characteristics are an important corporate goal that allows Évora cheese to increase in popularity with the consumer. This is the case of PDO products that need to acquire the acceptance of consumers while at the same time respecting their typical sensory attributes. The standardization and accreditation of sensory quality evaluation methods are needful for the certification of food products, with specific sensory characteristics, such as those with a protected designation of origin (PDO). We are certain that, the descriptive methodology of sensory analysis still stands as the most powerful and flexible tool, giving detailed information on all of a products' sensory properties in order to achieve a profile of products on all of its perceived sensory characteristics. In the future, it is predictable that descriptive analysis will be used increasingly for an extensive range of end uses than ever before. Considering this, it is crucial that investment continues in the development of descriptive analysis that challenges traditional ideas in order to guarantee optimal potential is gained from this method in the future.

\section{CONSENT FOR PUBLICATION}

Not applicable.

\section{CONFLICT OF INTEREST}

The authors declare no conflict of interest, financial or otherwise.

\section{ACKNOWLEDGEMENTS}

This work is funded by national funding through the FCT - Foundation for Science and Technology under Project UID/AGR/00115/2013. Funding was also provided by the European Regional Development Fund (FEDER), Alentejo Regional Operational Programme, through project ValBioTecCynara (ALT20-03-0145-FEDER-000038) Economic valorisation of cardoon (Cynara cardunculus): study of natural variability and biotechnological applications.

\section{REFERENCES}

[1] Köster EP. Diversity in the determinants of food choice: A psychological perspective. Food quality and preference $2009 ; 20(2)$ : 7082.

[2] Small DM, Prescott J. Odor/taste integration and the perception of flavor. Experimental Brain Research 2005; 166: 345-57.

[3] Estima CD, Philippi ST, ALVARENGA MD. Fatores determinantes de consumo alimentar: por que os indivíduos comem o que comem?. Revista brasileira de nutrição clínica 2009; 24(4): 263-8.

[4] Lamy E, Pinheiro C, Rodrigues L, Capela-Silva F, Lopes O, Tavares S, Gaspar R. Determinants of tannin-rich food and beverage consumption: oral perception vs. psychosocial aspects. Tannins 2016; 29-47

[5] Prescott J, Young O, O'Neill L, Yau N, Stevens, R. Motives for food choice: a comparison of consumers from Japan, Taiwan, Ma- laysia and New Zealand. Food quality and preference 2002; 13(7): 489-95.

[6] Gutjar S, de Graaf C, Palascha A, Jager G. Food choice: The battle between package, taste and consumption situation. Appetite 2014; 80: 109-13.

[7] Hough G, Sosa M. Food choice in low income populations: a review. Food Qual Prefer 2015; 40: 334-42.

[8] Ares G, de Saldamando L, Giménez A, AnnaClaretbLuís M.Cunhac Luis G, et al. Consumers' associations with wellbeing in a food-related context: A cross-cultural study. Food Qual Prefer 2015; 40: 304-15.

[9] Wang O, De Steur H, Gellynck X, Verbeke W. Motives for consumer choice of traditional food and European food in mainland China. Appetite 2015; 87: 143-51.

[10] Feldmann C, Hamm U. Consumers' perceptions and preferences for local food: A review. Food Qual Prefer 2015; 40: 152-64.

[11] Hetherington MM, Anderson AS, Norton GN, Newson L. Situational effects on meal intake: a comparison of eating alone and eating with others. Physiol Behav 2006; 88(4): 498-505.

[12] Dean M, Raats MM, Grunert KG, Lumbers M. Factors influencing eating a varied diet in old age. Public Health Nutr 2009; 12(12): 2421-7.

[13] Pieniak Z, Verbeke W, Vanhonacker F, Guerrero L, Hersleth M. Association between traditional food consumption and motives for food choice in six European countries. Appetite 2009; 53(1): 101-8.

[14] Hughner RS, McDonagh P, Prothero A, Shultz CJ, Stanton J. Who are organic food consumers? A compilation and review of why people purchase organic food. J Cons Behav 2007; 6(2-3): 94-110.

[15] Ekelund L, Fernqvist F, Tjärnemo H. Consumer preferences for domestic and organically labelled vegetables in Sweden. Acta Agriculturae Scand Section C 2007; 4(4): 229-36.

[16] Piggott JR. Sensory Analysis of Foods. 2rd ed. Elsevier Science Publishing 1988.

[17] Pinheiro C. Contributo para a caracterização do queijo de ovelha produzido na região de Évora: Aspetos químicos, bioquímicos do leite obtidos em diferentes sistemas de produção e físico-quimicos, bioquímicos, tecnológicos e organolépticos do queijo. PhD Thesis, University of Évora, Évora, Portugal, June 2002.

[18] Pinheiro C, Machado G, Bettencourt C, Matos C. Avaliação sensorial do queijo: Definição dos atributos de qualidade. Revista de Ciências Agrárias 2007; 30(1): 350-7.

[19] McSweeney PL. Biochemistry of cheese ripening. Inter J Dairy Technol 2004; 57(2-3): 127-44.

[20] Pinheiro C, Roseiro B. Atributos de Qualidade dos Queijos. International Meeting, Mérida, Espanha (1999).

[21] Reis PJ, Malcata FX. Current state of Portuguese dairy products from ovine and caprine milks. Small Ruminant Research 2011; 101(1): 122-33.

[22] Delahunty CM, Drake MA. Sensory character of cheese and its evaluation. Cheese: Chem, Phys Microbiol 2004; 1: 455-87.

[23] Lawless HT, Heymann H. Sensory evaluation of food: principles and practices. Springer Sci Bus Media 2010.

[24] Stone H, Bleibaum R, Thomas H. Sensory evaluation practices. Academic Press 2012.

[25] Ennis JM, Rousseau B, Ennis DM. Sensory difference tests as measurement instruments: A review of recent advances. J Sensory Stud 2014; 29(2): 89-102.

[26] Teixeira, LV. Análise sensorial na indústria de alimentos. Revista do Instituto de Laticinios Cândido Tostes 2009; 64(366): 12-21.

[27] Stone H, Sidel JL. Sensory evaluation practices. Sensory evaluation practices 2004.

[28] Ng M, Chaya C, Hort J. Beyond liking: Comparing the measurement of emotional response using EsSense Profile and consumer defined check-all-that-apply methodologies. Food Qual Pref 2013; 28(1): 193-205.

[29] King SC, Meiselman HL. Development of a method to measure consumer emotions associated with foods. Food Qual Pref 2010; 21(2): 168-77.

[30] Giles J, Lawrence RC. N. Z. J. Dairy Sci. Technol 1973; 8: 148-51.

[31] Pinheiro C, Marinho AA, Potes ES, Bento OP, Abreu MC. The artisanal cheese and its variability. Symposium on Animal Production and Rural Tourism in Mediterranean Areas, Évora, Portugal (1993).

[32] Bento OP, Pinheiro C; Machado J. The Effect of Ewe Breed on Sensory Characteristics of Évora Cheese. 6th International Con- 
gress of ICAF (International Committee of Anthropology of Food), Évora, Portugal (1995).

[33] Malcata, F., Reis, P., Madail, F., Pinho, L. Cheesemaking apparatus. EP1982582A2 (2008).

[34] Freitas AC, Macedo AC, Malcata FX. Review: Technological and organoleptic issues pertaining to cheeses with denomination of origin manufactured in the Iberian Peninsula from ovine and caprine milks. Food Sci Technol Inter 2000; 6(5): 351-70.

[35] Scintu MF, Piredda G. Typicity and biodiversity of goat and sheep milk products. Small Ruminant Res 2007; 68(1): 221-31.

[36] Fragata A, Alberto D, Coelho I. Social and economic impact of a PDO cheese ("Queijo de Nisa") on the local cheese production and processing (North of Alentejo, Portugal). Proceedings of the 2nd International Conference of the LSIRD Network. Bray, Dublin, December, 1999.

[37] Monteiro D, Lucas, M. Conjoint measurement of preferences for traditional cheeses in Lisbon. Bri Food J 2001; 103(6): 414-24.

[38] Elortondo FP, Ojeda M, Albisu M, Salmerón J, Etayo I, Molina M. Food quality certification: An approach for the development of accredited sensory evaluation methods. Food Qual Pref2007; 18(2): 425-39.
[39] Ribeiro JC, Santos JF. Region's reputation and the price of regional products: a hedonic analysis of Portuguese quality cheese 2004 .

[40] Tibério L, Diniz F. Agri-food traditional products: from certification to the market-Portuguese recent evolution. Reg Sci Inq J 2012; 4(2): 57-86.

[41] Bertozzi L, Panari G. Cheeses with Appellation d'Origine Contrôlée (AOC): Factors that affect quality. Inter Dairy J 1993; 3(46): 297-312.

[42] Elortondo FP, Barcenas P, Casas G, Salmeron J, Albisu M. Development of standardized sensory methodologies: some applications to Protected Designation of Origin cheeses. Sci Aliments 1999; 19: 543-58.

[43] Rivara JHC. Processo de preparação dos Queijos na Província do Alentejo. Portel 1835; 1-8.

[44] Pinheiro C, Banks J, Brechany E. Chemical and Sensory quality of Evora cheese, a hard ewe cheese. Proceedings of the 4th IDF Symposium on Cheese: Ripening, Characterization \& Technology, Prague, Czech Republic, March 21-25, 2004.

[45] Martins APL, Vasconcelos MM, Sousa RB. Thistle (Cynara cardunculus, L.) flower as acoagulantagent for cheesemaking. Short characterization. Le Lait 1996; 76(5): 473-7. 